\title{
General Design Issues of Sliding-Mode Controllers in DC-DC Converters
}

\author{
Siew-Chong Tan, Member, IEEE, Y. M. Lai, Member, IEEE, and Chi K. Tse, Fellow, IEEE
}

\begin{abstract}
This paper examines the practical design issues of sliding-mode (SM) controllers as applied to the control of dc-dc converters. A comprehensive review of the relevant literature is first provided. Major problems that prevent the use of SM control in dc-dc converters for industrial and commercial applications are investigated. Possible solutions are derived, and practical design procedures are outlined. The performance of SM control is compared with that of conventional linear control in terms of transient characteristics. It has been shown that the use of SM control can lead to an improved robustness in providing consistent transient responses over a wide range of operating conditions.
\end{abstract}

Index Terms-DC-DC converter, design issues, nonlinear controller, sliding-mode (SM) control.

\section{INTRODUCTION}

$\mathbf{T}$ HE SLIDING-MODE (SM) controller is a kind of nonlinear controller which was introduced for controlling variable structure systems (VSSs) [1]-[5]. Its major advantages are the guaranteed stability and the robustness against parameter, line, and load uncertainties [1]. Moreover, being a controller that has a high degree of flexibility in its design choices, the SM controller is relatively easy to implement as compared with other types of nonlinear controllers. Such properties make it highly suitable for control applications in nonlinear systems. This explains the wide utilization of SM controllers in various industrial applications, e.g., automotive control, furnace control, etc. [3]. Some recent works on SM control and its application can be found in [6]-[10].

Incidentally, characterized by switching, dc-dc converters are inherently variable-structured. It is, therefore, appropriate to use SM controllers for the control of dc-dc converters [11]. This seems more naturally so considering the excellent largesignal handling capability that the SM control can offer. Since the design of conventional pulsewidth-modulation (PWM) controllers in power electronics is small-signal-based, the system being controlled operates optimally only for a specific condition [12] and often fails to perform satisfactorily under large parameter or load variations (i.e., large-signal operating condition) [13]-[15]. By substituting the linear PWM controllers with SM (nonlinear) controllers in power converters, better regulation can be achieved for a wider operating range. This has aroused a

Manuscript received July 22, 2005; revised September 12, 2007

The authors are with the Department of Electronic and Information Engineering, Hong Kong Polytechnic University, Kowloon, Hong Kong (e-mail: ensctan@polyu.edu.hk).

Digital Object Identifier 10.1109/TIE.2007.909058 lot of interest in the use of SM controllers for dc-dc converters [16]-[66].

However, despite being a popular research subject, SM control is still rarely applied in practical dc-dc converters. There are various reasons accommodating this. First, unlike PWM controllers, SM controllers are not available in integrated-circuit (IC) forms for power-electronic applications. Second, there is a lack of understanding in their design principle by power-supply engineers. No systematic procedure is available for the design of SM controllers. Third, there is a strong reluctance to the employment of SM controllers in $\mathrm{dc}-\mathrm{dc}$ converters because of their inherently high and variable switching frequency, which causes excessive power losses, electromagnetic-interference (EMI) generation, and filterdesign complication. Fourth, all discussions regarding the usefulness and advantages of SM controllers have been theoretical. The practical worthiness of using SM controllers is generally unproven. In essence, SM controllers are not used in practical $\mathrm{dc}-\mathrm{dc}$ converters because of the inconvenience of using them, as well as the lack of strong evidence to support the need for using them. These explain why the application of SM controllers in dc-dc converters has only been of academic/research interest but of little industrial value. Specifically, as the theoretical groundwork of SM control is fairly matured, it is timely to direct more research efforts toward developing practical SM controllers for dc-dc converters. This will enable the industry to truly benefit from the advantages of designing power supplies based on the SM paradigm.

Hence, the objective of this paper is to present an overall discussion to clarify the different aspects of the application of SM controllers in dc-dc converters. A comprehensive literature review is conducted to update practicing engineers about the previous and ongoing works in the area. The various problems of applying SM controllers to dc-dc converters are discussed. The practical issues related to its implementation are also addressed. The aim is to provide practicing engineers with feasible solutions that can be adopted for the development of practical SM controllers for dc-dc converters. Finally, the advantages of using the SM controllers as compared with the conventional linear controllers are discussed through some case-study examples.

\section{LiteratuRE REVIEW}

The literature review is organized under several categories of discussions. This is to provide a clear historical overview of the major stages of development in this area. 


\section{A. Earliest Works}

The earliest works on developing SM controllers for dc-dc converters were reported in 1983 [16] and 1985 [17]. Bilalović et al. [16], the earliest group that worked in this area, demonstrated how SM controllers can be applied to dc-dc converters. However, their work was preliminary and focused only on the buck converter. Later, Venkataramanan et al. [17] presented a more complete description of how SM control can be applied to all different basic topologies of second-order $\mathrm{dc}-\mathrm{dc}$ converters. They also showed the idea of relating the equivalent control method of SM-control theory to the dutyratio control method of PWM technique to achieve constantfrequency SM controllers. This will be discussed in-depth later in this paper.

\section{B. Higher Order Converters}

After Venkataramanan et al. [17] published their work on second-order dc-dc converters, Huang et al. [18] experimented the SM controller on a more complex fourth-order Ćuk converter in 1989. This spurred a series of related works on the Ćuk converter. In 1992, Fossas et al. [19] examined the audiosusceptibility and load-disturbance properties of the SM-controlled Ćuk converter. In 1995, Malesani et al. [20] systematized the design approach for the SM-controlled Ćuk converter. In 1996, Oppenheimer et al. [21] implemented the SM controller on a third-order-type Ćuk converter. Moreover, in 1996, Mahdavi and Emadi [22] developed the first PWM-based SMcontrolled Ćuk converter. Then, in 1997, Calvente et al. [23] introduced a method of designing locally stable SM controller for the bidirectional coupled-inductor Ćuk converter, and in 1998 , they provided a thorough analytical evaluation of the converter [24].

At the same time, the work of Huang et al. [18] also generated new interest on other types of higher order $\mathrm{dc}-\mathrm{dc}$ converters. In 1993, Mattavelli et al. [25] proposed a generalpurpose SM controller which is applicable for both Cuk and single-ended primary inductance (SEPIC) converter. In 1997, the same group extended the research by proposing a method of deriving the small-signal models of these converters, which allows the investigation of stability and the selection of the control parameters [26]. In 1994, Dominguez et al. [27] performed a stability analysis of an SM-controlled buck converter with an input filter. In 2000, Castilla et al. [28] presented the design methodology of the SM-control schemes for quantum resonant converters.

\section{Parallel-Connected Converters}

The interest in applying SM control to more complex types of dc-dc converters has also covered the class of parallelconnected dc-dc converters. In 1996, Donoso-Garcia et al. [29] and Shtessel et al. [30] proposed the use of SM control to achieve current equalization and output-voltage regulation of modular dc-dc converters. In 1998, Shtessel et al. [31] suggested that dynamic sliding surface can be employed for better stabilization and control of such modular converters.
In addition, in 1998, López et al. [32] proposed the use of SM control for interleaving parallel-connected dc-dc converters. However, the illustration was only limited to the buck-type modular converters. Then, in 2000, Giral et al. [33] demonstrated the application of SM controllers for interleaved boost converters.

In 2002, Mazumder et al. [34] combined the integralvariable-structure and multiple-sliding-surface control schemes to nullify the bus-voltage error and the error between the load currents of the parallel-connected converter modules. In 2004, López et al. [35] presented a detailed paper on the analysis and design of an SM-controlled parallel-connected boost-converter system. In comparison with the papers [29], [30], [31], and [34], which address the basic theory, the work of López et al. [35] is more relevant to practical power electronics.

\section{Theoretical Works}

Due to simplicity and ease of analysis, simple second-order dc-dc converters have been the subject of investigation in much of the previous works. The main focus was the theoretical derivation of SM-control methodologies. These earlier studies have played an important role in the development of practical SM controllers for dc-dc converters.

In 1994, Sira-Ramirez and Rios-Bolivar [36] proposed the use of an extended linearization method in SM-controller design that results in SM controllers that have excellent selfscheduling properties. In 1995, they proposed to incorporate passivity-based controllers into the SM-controlled dc-dc converter to enhance its robustness properties [37], [38]. In 1996, Fossas and Biel [39] presented a new approach for the design of SM-controlled dc-dc converters for generating an ac signal. In 1997, Carrasco et al. [40] proposed to incorporate neural networks with SM controllers for power-factor-correction applications.

In 2001, Bock et al. [41] proposed a design procedure for the selection of high-pass-filter parameters of the SM-controlled bidirectional dc-dc converters. In 2002, Fossas and Pas [42] applied a second-order SM controller to a buck converter to reduce the chattering. Furthermore, in 2002, Shtessel et al. proposed two SM-control strategies for boost and buck-boost converters: one using the method of stable system center [43] and the other using the dynamic sliding manifold [44].

In 2003, Vazquez et al. [45] proposed a new sliding surface that eliminates the use of a current sensor, and Gupta and Patra [46] proposed a hybrid SM controller that employs a combined form of voltage and current sliding surfaces to improve robustness. In addition, in 2003, Sira-Ramirez [47] proposed a hysteresis modulation type of SM controller to achieve a generalized proportional integral (GPI) continuous control of a buck converter. He also presented a tutorial that revisits and evaluates the performances of direct and indirect SM-controller schemes and proposed the use of GPI control technique to improve the robustness of the system with respect to unmodeled load-resistance variations [48].

Apart from developing SM-control theory for powerconverter applications, evaluations of performance and comparisons with other control methods were also reported. In 
1997, Raviraj and Sen [49] made a comparative study of the buck converter's performance when controlled by PI, SM, and fuzzy-logic controllers. They concluded that there are some similarities in the system's behavior between fuzzy-logic and SM controllers. In 2002, Cortes and Alvarez [50] revisited the work on the SM control of boost converters by comparing and analyzing the performances using different proposed schemes and sliding surfaces. In 2002, Morel et al. [51]-[53] studied the nonlinear behavior exhibited by the conventional current-modecontrolled boost converter and proposed the alternative use of SM controller to eliminate the chaotic behavior of the converter.

In summary, the objectives of most previous works are to simplify design procedures, enhance robustness, reduce the number of components, and prevent chattering.

\section{E. Practical Works}

A few experimental evaluations of SM-controlled dc-dc converters have been reported in the literature. Most of the reported experimental works, however, focused their attention on performance evaluation rather than on developing design procedures.

In 1999, Escobar et al. [54] performed experiments to compare five different control algorithms, including the SM-control scheme, on a dc-dc boost power converter. They concluded that nonlinear controllers provide a promising alternative to the linear average controller, which performs poorly in tracking timevarying references. Furthermore, in 1999, Chiacchiarini et al. [55] conducted an experiment to compare the performances of a buck converter controlled by digital and analog SM controllers. They concluded that the SM-controlled system gives consistent responses despite variation in load conditions.

In 2001, Alarcon et al. [56] reported the first analog IC SMcontrol prototype for $\mathrm{dc}-\mathrm{dc}$ converters. They concluded that the megahertz operating range of the controller fits the requirements supported by modern power-electronic technologies. In 2003, Ahmed et al. [57], [58] first implemented and then provided an experimental evaluation of the dynamic performance of an SM-controlled buck converter. In another paper [59], they also implemented the SM controller on a buck-boost converter using the control desk dSPACE.

\section{F. Constant-Frequency SM Controllers}

Some researchers have noted the importance of maintaining a constant switching-frequency operation in their SM-controlled converter systems.

In 1992, Cardoso et al. [60] proposed several methods of reducing the switching frequency of the SM-controlled dc-dc converters. In 1995, Nguyen and Lee [61] proposed an adaptive hysteresis type of SM controller to ensure constant switching frequency. In 1996, they proposed an indirect method of implementing SM controllers in buck converters so that constant switching frequency can be achieved [62]. In 1997, Mahdavi et al. [63] proposed a method of deriving PWMbased SM-controlled dc-dc converters that have a constant switching frequency. Later, in 2000, they extended the work by incorporating neural networks into their PWM-based SM con- trollers [64]. In 2004, Perry et al. [65] proposed a digital fuzzylogic SM-like controller that has a fixed switching frequency and provides zero steady-state error, and Iannelli and Vasca [66] proposed a method of dithering to maintain a finite and constant switching frequency. In addition, in 2004, Mazumder and Kamisetty [67] gave an experimental validation of their proposed control scheme [34] for the parallel converters, which not only optimizes the transient and steady-state responses but also achieves a constant switching frequency at steady state.

SM control has, in most cases, been studied in continuous time. A few attempts to study its discrete-time counterparts have been reported. In 2000, Matas et al. [68] proposed a discrete-time SM-controlled boost converter for output-voltage tracking, and Orosco and Vazquez [69] provided a complete analysis of the discrete-time SM-controlled dc-dc converters. They argued that the discrete-time implementation of the SM controller can overcome the inherent drawbacks of variable switching-frequency operation in the conventional continuoustime implementation.

\section{G. Remarks}

In concluding the literature survey, the major developments of SM control in dc-dc converters are summarized as follows, along with some comments on the likely directions for current and future research developments.

First, the idea of applying SM (nonlinear) control in highorder converter systems is acceptable by large since linear controllers are incapable of providing good control over such systems. Higher design and implementation costs can be easily justified in such circumstances. On the other hand, the idea of applying SM controllers to basic second-order dc-dc converter topologies is often challenged and is by and large unpopular even within the research community. The main complaint is the conceptual/implemental complexity of the control scheme as compared with the existing linear controllers, which are already offering acceptable control properties in such converters for most applications. Moreover, the notion of using relatively higher cost digital means to implement the SM controllers, as illustrated in many previous attempts, has been deemed unrealistic for commercial applications. Hence, it is important to find out what the benefits and drawbacks of using SM controllers are, as compared to the existing linear PWM controllers, assuming that it is possible to implement the former in a comparable form and cost with the latter.

Second, it can be concluded that a large part of the previous effort has been devoted to the development of the theoreti$\mathrm{cal} /$ mathematical framework of SM control for dc-dc converters. Practical work, however, has been very much neglected due to the conventional belief that the derived SM-control schemes can be easily realized in digital forms. Thus, the interest in its development normally halts at the theoretical/mathematical stages. However, considering that if SM controllers are to be implemented for commercial applications, thorough studies of practical problems are necessary. Specifically, the different means of developing analog SM controllers, which operate at a constant switching frequency in compliance with the usual industrial standard, should be explored. Yet, under such design 
criteria, a contradiction exists between the ideal operation of SM controllers at infinitely high frequency and the practical constraint of physical converter systems that are only allowed to operate at limited frequency ranges. Thus, while aiming at competitive pricing and compatible standard with the existing PWM controllers, there must also be considerations on how the nonideality of finite switching frequency can be compromised in practical SM controllers without sacrificing the large-signal properties of SM control. Essentially, more investigations into such aspects are still required.

In conclusion, before SM controllers can be commercially viable in common $\mathrm{dc}-\mathrm{dc}$ converter applications, the aforementioned issues should first be overcome. This may prove to be difficult considering that many still regard the work on the application of SM controllers in simple second-order converters as redundant and impractical. Hence, before it is possible to proceed with further investigation, the viability of using SM controllers for simple converters has to be clearly demonstrated. For instance, it has been shown in some recent works [25], [55], [56], [70] that SM controllers can be implemented in terms of simple analog circuits.

\section{SLIDING-Mode Controllers}

This section gives a summarized overview of the various aspects of the SM controllers, particularly for applications in $\mathrm{dc}-\mathrm{dc}$ converters.

\section{A. Ideal Controller}

The basic principle of SM control is to employ a certain sliding surface as a reference path such that the controlled state variables' trajectory can be directed toward the desired equilibrium. Theoretically, such ideology of the SM control can be fully achieved only with the absolute compliances of certain conditions, namely, the hitting condition, the existence condition, the stability condition, and the condition that the system operates at an infinite switching frequency.

In such respect, what is derived is an idealized controlled system, whereby no external disturbances or system's uncertainties can affect the ideal control performance of having zero regulation error and very fast dynamic response. Hence, in a certain sense, the SM controller is actually a type of ideal controller for the class of VSSs.

\section{B. Applications to DC-DC Converters}

"Practically all design methods for VSSs are based on deliberate introduction of sliding modes which have played, and are still playing, an exceptional role both in theoretical developments and in practical applications."

This statement is extracted from the preface of [1] by Utkin et al. If such a reasoning is elaborated in the context of power electronics, a logical deduction follows that since all power-electronic converters are intrinsically variablestructured, their control methodologies, be it linear or nonlinear, are all based on some form of SM control. This is true since the objectives of all controllers in the dc-dc converters share the same formula of switching between multiple structures to achieve a desired output. Ultimately, they are all tracking some kind of sliding surfaces, each uniquely defined by its control strategy, to achieve equilibrium. Therefore, the difference between the conventional control methodologies and the actual SM-control methodology can be distinguished by the way in which the controllers are being designed. For the conventional control methodologies, the sliding surfaces are indirectly formulated through the design of the control parameters and controller's type, which are determined by some stability analysis. The controller designers are neither informed nor have they any direct control on how the sliding surfaces are constructed. For the SM control, however, the design procedure starts with the formulation of the sliding surfaces. The controller designers always determine the type of sliding surfaces they desire, and this allows them to exercise a direct control over the dynamic response of the system. The way in which the control parameters are chosen is then purely defined by the hitting condition, the existence condition, and the stability condition of the SM-control law.

These viewpoints have brought new insights to how different control objectives can be achieved in power-electronic converters.

\section{Principle of Operation}

The basic principle of SM control is to design a certain sliding surface in its control law that will direct the trajectory of the state variables toward a desired origin when coincided. In the case of a single switch dc-dc converter, it is appropriate to have a control law that adopts a switching function such as

$$
u=\frac{1}{2}(1+\operatorname{sign}(S))
$$

where $u$ is the logic state of the converter's power switch, and $S$ is the instantaneous state variable's trajectory which, in the case of a second-order controller, is described as

$$
S=\alpha_{1} x_{1}+\alpha_{2} x_{2}+\alpha_{3} x_{3}
$$

where $\alpha_{1}, \alpha_{2}$, and $\alpha_{3}$ represent the control parameters, usually referred to as sliding coefficients, and $x_{1}, x_{2}$, and $x_{3}$ denote the desired state feedback variables to be controlled. By enforcing $S=0$, a sliding surface (plane), as shown in Fig. 1, can be obtained.

A detailed discussion of the SM-control principle can be found in [1]. In brief, the entire SM-control process can be divided into two phases. In the first phase (reaching phase), regardless of the starting position, the controller will perform a control decision that will drive the trajectory of the state variables to converge to the sliding surface [see Fig. 1(a)]. This is possible through the compliance of the so-called hitting condition $^{1}[3]$.

When the trajectory is within a small vicinity of the sliding surface, it is said to be in SM operation, which is the second

\footnotetext{
${ }^{1}$ Satisfaction of the hitting condition assures that, regardless of the initial condition, the state trajectory of the system will always be directed toward the sliding surface.
} 


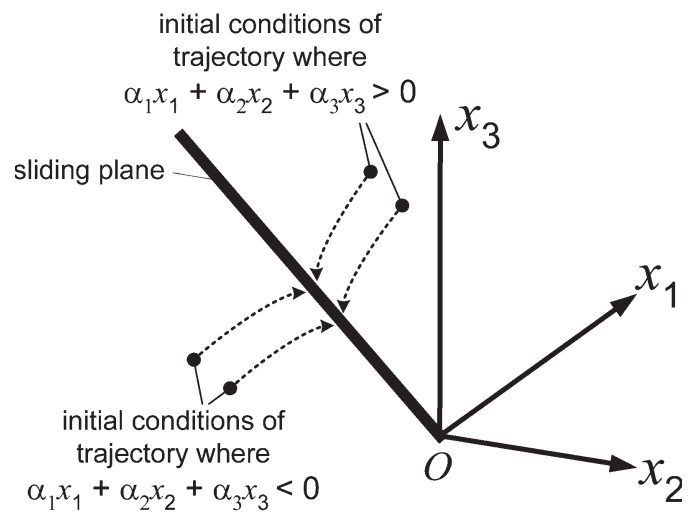

(a)

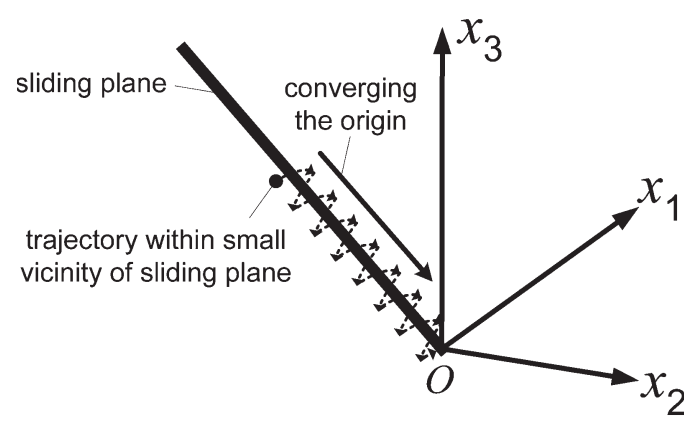

(b)

Fig. 1. Graphical representations of state variables' trajectory behavior in SM control process. (a) Phase 1 -illustrating trajectory converging the sliding plane irrespective of its initial condition. (b) Phase 2-illustrating trajectory being maintained within a small vicinity from the sliding plane and concurrently being directed to converge to the origin $O$.

phase of the control process. The controller will give a series of control actions via switching such that the trajectory is maintained within a small vicinity of the sliding surface and is concurrently directed toward the desired reference at origin $O$ [see Fig. 1(b)]. In other words, the SM controller is performing its control decision by utilizing the sliding plane as a reference path, on which the trajectory will track and eventually converge to the origin to achieve steady-state operation. This is possible by satisfying the so-called existence condition ${ }^{2}$ and stability condition $^{3}[3]$.

Hence, when the system enters into SM operation, its equivalent trajectory can be ideally described as $S=0$. This also defines the dynamic characteristic of the system, which can be designed by the proper choice of control parameters, i.e., sliding coefficients [71].

\section{Constant Dynamics}

An interesting property of the SM controller is its capability of providing constant system's dynamics during SM operation. Using the same example, the transient dynamics for

\footnotetext{
${ }^{2}$ Satisfaction of the existence condition ensures that the state trajectory at locations near the sliding surface will always be directed toward the sliding surface.

${ }^{3}$ Satisfaction of the stability condition ensures that the state trajectory of the system under SM operation will always reach a stable equilibrium point.
}

the SM-operation phase can be obtained by equating (2) as $S=0$, i.e.,

$$
\frac{d^{2} x_{1}}{d t^{2}}+\frac{\alpha_{1}}{\alpha_{2}} \cdot \frac{d x_{1}}{d t}+\frac{\alpha_{3}}{\alpha_{2}} \cdot x_{1}=0
$$

when operated at the nominal load resistance $R_{\mathrm{L}(\text { nom })}(t)$. However, in the case when the load deviates from the nominal design condition, the system dynamics will be changed to

$$
\frac{d^{2} x_{1}}{d t^{2}}+\left(\frac{\alpha_{1}}{\alpha_{2}}+\frac{1}{r_{\mathrm{L}}(t) C}-\frac{1}{R_{\mathrm{L}(\mathrm{nom})}(t) C}\right) \cdot \frac{d x_{1}}{d t}+\frac{\alpha_{3}}{\alpha_{2}} \cdot x_{1}=0
$$

where $r_{\mathrm{L}}(t) \neq R_{\mathrm{L}(\text { nom) }}$ is the instantaneous load resistance. It is possible by choosing $\left(\alpha_{1} / \alpha_{2}\right) \gg\left(1 / r_{\mathrm{L}} C\right)$ to ensure an almost constant dynamical characteristic for the SM-operation phase throughout all operating conditions. Note that such property only applies to the SM-operation phase and not to the reaching phase, which has a different dynamic characteristic for each operating condition. Yet, considering that the time taken to complete the SM-operation phase is usually much greater than the reaching phase, it is sufficient to consider only the dynamics of the former for the controller design. Hence, it is possible to have a system that can attain constant dynamical behavior using the SM controller.

This is not the case for the conventional types of linear PWM controllers. It is well known that the small-signal structure of the linear controllers can allow the dynamics of the system to be characterized at only one specific operation condition. Hence, when the operating condition differs from the nominal condition, the dynamical response of the system will be different. A comparison of these properties is given in the later part of the paper.

\section{E. Quasi-Sliding-Mode (QSM) Control}

Ideally, to achieve a perfect SM-control operation, the system must be operated at an infinite switching frequency so that the controlled variables can exactly follow the reference track to achieve the desired dynamic response and steadystate operation [1]. This requirement for operation at an infinite switching frequency, however, challenges the feasibility of applying SM controllers in dc-dc converters. This is because extreme high-speed switching in dc-dc converters results in excessive switching losses, inductor and transformer core losses, and EMI-noise issues. Hence, for SM controllers to be applicable to dc-dc converters, their switching frequencies must be constricted within a practical range. Different methods (hysteresis, constant sampling frequency, constant ON time, constant switching frequency, and limited maximum switching frequency) were proposed to limit the switching frequency [60]. However, they fall short of a set of systematic design methods and implementation criteria.

Nevertheless, this constriction of the SM controller's switching frequency transforms the controller into a type of QSM controller, which operates as an approximation of the ideal SM controller. The consequence of this transformation is the reduction of the system's robustness and the deterioration of 
the regulation properties. Clearly, the proximity of QSM to the ideal SM controller will be closer as the switching frequency increases. Since all SM controllers in practical dc-dc converters are frequency-limited, they are, strictly speaking, QSM controllers. Typically, the term SM controller has been adopted to represent QSM controller in many research papers.

\section{F. Conventional Hysteresis-Modulation (HM)-Based Sliding-Mode Controller}

The conventional method of implementing the SM controller is based on the control law described in (1) and (2). The former is a type of signum function and is easily realized using a switch relay. The latter, which computes the instantaneous state-variable trajectory $S$, is realized through an analog or digital computer. However, the direct implementation of this control law results in converters that are switched at very high and uncontrolled frequency [1], [70]. As mentioned previously, this makes it unsuitable for the converter's control purpose. Hence, it is necessary to suppress the operating frequency into a controllable form. Of the many methods proposed, the most popular is the HM method. This method does not require additional computation or auxiliary circuitries, and its implementation is easily accomplished by refining (1) into

$$
u= \begin{cases}1=\text { "ON," } & \text { when } S>\kappa \\ 0=\text { "OFF, } & \text { when } S<-\kappa \\ \text { previous state, }, & \text { otherwise }\end{cases}
$$

where $\kappa$ is an arbitrarily small value. The introduction of a hysteresis band with the boundary conditions $S=\kappa$ and $S=$ $-\kappa$ provides a form of control to the switching frequency of the converter, thus solving the practical problem of a very high frequency switching operation. However, due to the lack of systematic design methods and implementation criteria, the implementation of HM-based SM controllers for dc-dc converters still relies on the trial-and-error tuning of the $\kappa$ magnitude to achieve the desired switching frequency for a specific operating condition. A method of formulating this design equation for buck converter has recently been proposed in [70].

\section{The NeEd for FiXed-Frequency SM Controller}

Despite the imposition of the hysteresis band upon the switching relay to suppress the switching frequency, the problem of variable switching-frequency operation still exists. It has been shown that HM-based SM-controlled converters generally suffer from significant switching-frequency variation when the input voltage and the output load are varied [25], [70]. This complicates the design of the input and output filters. Obviously, designing the filters under a worst case (lowest) frequency condition will result in oversized filters. Moreover, the variation of the switching frequency also deteriorates the regulation properties of the converters. Furthermore, it is well known that switching converters are severe noise generators. The task of containing noise can be made easier with fixedfrequency operation. It is therefore necessary to have the SMcontrolled converters operate at a constant switching frequency for all operating conditions.

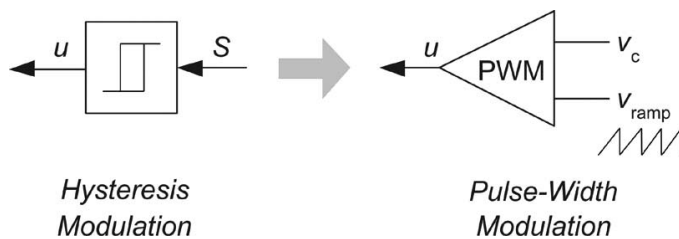

Fig. 2. Simplified HM and PWM structure.

According to the literature, there are basically two approaches in keeping the switching frequency of the HM-based SM controller constant. One approach is to incorporate a constant ramp or timing function directly into the controller [25], [60], [66]. The main advantage of this approach is that the switching frequency is constant under all operating conditions and can be easily controlled through varying the ramp/timing signal. However, this comes at the expense of additional hardware circuitries, as well as deteriorated transient response in the system's performance caused by the superposition of the ramp function upon the SM switching function.

The second approach is to include some forms of adaptive control into the HM-based SM controller to contain the switching-frequency variation [61]. For line variation, the frequency variation is alleviated through the adaptive feedforward control, which varies the hysteresis band with the change of the line input voltage. For load variation, the frequency variation is alleviated through the adaptive feedback control, which varies the control parameter (i.e., sliding coefficient) with the change of the output load. Conceptually, these methods of adaptive control are more direct and less likely to suffer from deteriorated transient response. However, the architecture of the resulting controller is relatively more complex and may increase the implementation cost of the controller.

On the other hand, constant switching-frequency SM controllers can also be obtained by employing PWM instead of HM [62]. In practice, this is similar to classical PWM control schemes in which the control signal is compared to the ramp waveform to generate a discrete gate pulse signal [13]. The advantages are that additional hardware circuitries are not needed since the switching function is performed by the PWM modulator and that its transient response is not deteriorated. However, the implementation is nontrivial in order to preserve the original SM control law, particularly if both the current and voltage state variables are involved. Hence, this approach is not always implementable for some SM-controller types. As this is an unconventional and relatively new topic, more discussion is provided in the following section.

\section{A. Pulsewidth-Modulation-Based Sliding-Mode Controller}

Fig. 2 shows the idea of the PWM-based SM controller, where PWM is used in lieu of HM without destroying the SMcontrol properties. This requires the relationship of the two control techniques to be established. Two key results are useful here. First, in the SM control, the discrete control input (gate signal) $u$ can be theoretically replaced by a smooth function known as the equivalent control signal $u_{\text {eq }}$, which can be formulated using the invariance conditions by setting the time differentiation of (2) as $\dot{S}=0$ [1]. Second, at a high switching 


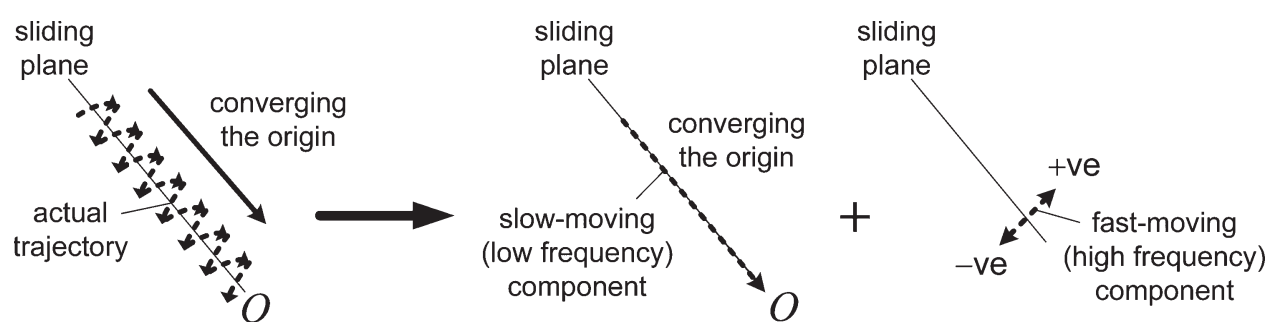

Fig. 3. Graphical representation of high- and low-frequency components of the state trajectory.

frequency, the equivalent control is effectively a duty-cycle control [72]. Since a duty cycle is also basically a smooth analytic function of the discrete control pulses in PWM, a PWM-based SM controller can be obtained by mapping the equivalent control function onto the duty-cycle function $d$ of the pulsewidth modulator, i.e., $d=u_{\text {eq }}$.

Interestingly, the derived PWM-based SM controllers can also be viewed as a type of nonlinear state feedback controllers designed from some nonlinear "per-cycle averaged models" of the converters. However, it should be emphasized that a main difference between the two approaches is that, while an "average model" is assumed, the PWM-based SM controller approach, which only performs averaging during the controller implementation, retains much of the converter dynamics. This results in a set of design restrictions: the existence condition, which arises from the instantaneous dynamics of the converter, as required by the SM control. Such a design restriction is absent from the conventional nonlinear PWM controller design approach.

An insight to the theory of the equivalent control and the duty-ratio control is provided next.

\section{B. Equivalent Control}

As discussed, to achieve an ideal SM-control operation, the system must be operated at an infinite switching frequency so that the state variables' trajectory is oriented precisely on the sliding surface. However, in the practical case of finite switching frequency, the trajectory will oscillate in some vicinity of the sliding surface while moving toward the origin [see Fig. 1(b)]. It is possible to identify the movement of the trajectory as a composition of two isolated components: a fastmoving (high-frequency) component and a slow-moving (lowfrequency) component.

Fig. 3 shows a graphical representation of the state trajectory being separated into a high-frequency component and a lowfrequency one. It can be seen from the diagram that the highfrequency component is actually a discontinuous trajectory that alternates between the +ve and -ve direction, whereas the low-frequency component is actually a continuous trajectory that moves along the sliding plane. Since the movement of the trajectory is a consequence of the switching action $u$, it is therefore possible to relate the corresponding low- and highfrequency components of the trajectory to a low-frequency continuous switching action $u_{\text {low }}$, where $0<u_{\text {low }}<1$, and to a high-frequency discontinuous switching action $u_{\text {high }}$, where $u_{\text {high }}=-u_{\text {low }}$ or $1-u_{\text {low }}$, and that $u=u_{\text {high }}+u_{\text {low }}$. Under such assumptions, the switching action of $u_{\text {high }}$ produces only the high-frequency trajectory component, and the switching action of $u_{\text {low }}$ produces only the low-frequency trajectory component.

Now, ignoring the high-frequency component, which is often filtered out by the plant, ${ }^{4}$ the motion of the trajectory is then solely determined by the low-frequency component. Hence, it is reasonable to consider only the low-frequency continuous switching action $u_{\text {low }}$ as the desired switching action that will produce a trajectory that is of near equivalence to an ideal SMoperation trajectory. This is the so-called equivalent control. Therefore, the often used terminology, the equivalent control, i.e., $u_{\text {eq }}$, is actually the low-frequency continuous switching action $u_{\text {low }}$ described earlier. The method of obtaining the equivalent control is given as follows.

First, consider a system $\dot{x}=f(x, u)$, where $u=(0,1)$. In an ideal SM operation, the state trajectory $S$ is always moving along the sliding plane, i.e., $S=0$, and without any high-frequency oscillation, it is also true that $d S / d t=\dot{S}=0$. Next, consider that the equivalent control produces a trajectory whereby its motion is exactly equivalent to the trajectory's motion of an ideal SM operation. Under such assumptions, the state trajectory equation $\dot{S}=G \cdot f(x, u)$, where $G=\partial S / \partial x$, can be rewritten as $\dot{S}=G \cdot f\left(x, u_{\mathrm{eq}}\right)$. Then, the solution of the equivalent control $u_{\text {eq }}$ can be obtained by solving $G$. $f\left(x, u_{\text {eq }}\right)=0$. Finally, if $u_{\text {eq }}$ is substituted back into the original system

$$
\dot{x}=f\left(x, u_{\text {eq }}\right)
$$

which is the motion equation of the converter operating in SM operation, can be obtained. This method of deriving the equivalent control signal $u_{\mathrm{eq}}$, as well as the insertion of the signal into the original system to formulate the motion equation as shown in (6), is known as the equivalent control method [1].

\section{Duty-Ratio Control}

In conventional PWM control, which is also known as the duty-ratio control, the control input $u$ is switched between 1 and 0 once every switching cycle for a fixed small duration $\Delta$. The time instance at which the switching occurs is determined by the sampled value of the state variables at the beginning of each switching cycle. Duty ratio is then the fraction of the switching cycle in which the control holds the value of one. It is normally

\footnotetext{
${ }^{4}$ Note that, in the case of dc-dc converters, the high-frequency ac signals are filtered out by the output filter capacitor.
} 
a smooth function of the state vector $x(t)$, and it is denoted by $d(x)$, where $0<d(x)<1$. Then, for each switching cycle interval $\Delta$, the control input $u$ can be written as

$$
u= \begin{cases}1, & \text { for } t \leq \tau<t+d(x) \Delta \\ 0, & \text { for } t+d(x) \Delta \leq \tau<t+\Delta\end{cases}
$$

It follows that a system $\dot{x}=f(x, u)$ can be expressed as

$$
x(t+\tau)=x(t)+\int_{t}^{t+d(x) \Delta}[f(x(\tau))] d \tau+\int_{t+d(x) \Delta}^{t+\Delta} 0 d \tau .
$$

The ideal average model of the PWM-controlled system response is obtained by allowing the duty-cycle frequency to tend to infinity, i.e., $\Delta$ to approach zero. Under such consideration, the earlier equation becomes

$$
\frac{\lim _{\Delta \rightarrow 0}[x(t+\Delta)-x(t)]}{\Delta}=\frac{\lim _{\Delta \rightarrow 0}\left[\int_{t}^{t+d(x) \Delta} f(x(\tau)) d \tau\right]}{\Delta}
$$

i.e.,

$$
\frac{d x}{d t}=\dot{x}=f(x, d)
$$

which is referred to as the average PWM-controlled system. Therefore, it is shown that, as the duty-cycle frequency tends to infinity, the ideal average behavior of the PWM-controlled system is represented by the smooth response of the system constituted by the duty ratio $d(x)$. It should also be noted that the duty ratio $d(x)$ replaces the discrete function $u$ in the same manner as the equivalent control $u_{\mathrm{eq}}$ of the SM-control scheme to obtain (6). Hence, the relationship $d(x)=u_{\mathrm{eq}}(x)$ is established [72].

\section{Practical Issues in IMPLEMENTATION: AN ANALOG VIEWPOINT}

There are a few works addressing the practical aspects of implementing the SM controller for dc-dc converters, specifically in the area of analog implementation. This results in the lack of understanding in its design principle. Issues like the requirement for constant switching-frequency operation in the SM controller and the need to redefine the sliding coefficients to meet the practical component constraints have been covered in [60]-[70]. Here are a few aspects related to the analog implementation of the SM controller, which also deserve consideration.

First, the choice of system's state variables, i.e., voltage, current, and their derivatives and/or integrals, is important in that it affects not only the control performance but also the complexity of the implementation. These are a few questions that should be considered.

1) How many state variables to control?

Comment: The higher the number of state variables, the higher the degree of system's controllability. How- ever, more sensing and/or computations of the state variables are required.

2) Which state variables to control?

Comment: The use of voltage state variables is easier because of the simplicity of implementing voltage sensors. However, the choice for their derivatives may require the use of noise sensitive differentiators. Alternatively, indirect means of sensing such state variables is possible, e.g., $d v_{\mathrm{o}} / d t$ can be found by sensing the current of the output capacitor. Yet, this will lead us to the subsequent question as to whether it is convenient to perform such sensing.

On the other hand, an integral term of the controlled variable $\int x$ is often required to reduce the steady-state error of the system, which may otherwise exceed the regulation requirement.

3) Is the location accessible or feasible for such sensing?

Comment: The sensing of capacitor current to find the derivative of voltage variable is not always the best option. This is particularly true for the case where the capacitor is a filter capacitor. The addition of a current sensor in its current flow path will increase the impedance and therefore deteriorate the filtering process.

4) What types of sensors are required?

Comment: For the sensing of the filtering capacitors' currents, very low impedance current transformers are normally required. However, for sensing currents that have dc average components, resistors or sophisticated Hall-effect sensors may be required. These may affect the overall efficiency or cost of the dc-dc converters.

Moreover, for the PWM-based SM controllers, the indirect implementation of the original SM control law may result in unexpected complications in the signal computation and is therefore not always implementable for some SM controller types. Hence, the choice for the state variable is critical for the successful implementation of an analog SM controller.

Finally, similar to conventional controllers, the physical limitation of the analog devices, e.g., bandwidths, propagation time delays, slew rates, and saturation limits, of the SM controller should be properly noted. They are the key factors affecting the healthy operation of the SM controller. More work is still required in such areas of investigation.

\section{Practical Design Guides}

Since SM control can achieve order reduction, it is typically sufficient to have an SM controller of $n-1$ order for the stable control of an $n$-order converter. However, if fixed-frequency SM controllers are to be employed, the robustness and regulation properties of the converter system under the orderreduced SM controller will be deteriorated. A good method of alleviating these deteriorations is to introduce an additional integral control variable into the fixed-frequency SM controller. This is known as integral or full-order SM control since the SM controller is now of the same order as the converter [1]. The function of making the SM controller full-order is to improve the robustness, as well as the regulation, of the system. Hence, in terms of ease of implementation and control performance, a 
good option is to adopt an SM controller that employs a linear combination of the system states, which has the same order as the converter.

Now, assuming that a full-order sliding-mode controller is designed for a basic second-order converter, the control function of such a second-order controller is

$$
u= \begin{cases}u^{+}, & \text {when } S>0 \\ u^{-}, & \text {when } S<0\end{cases}
$$

where $S$ takes the form as described in (2). The task of the designer is to determine the state of $u^{+} / u^{-}$and to select proper parameters for $\alpha_{1}, \alpha_{2}$, and $\alpha_{3}$ such that the controller meets the hitting, existence, and stability conditions for all of the system's operating input and loading conditions.

\section{A. Step 1: To Meet Hitting Condition}

The design of the SM controller to meet the hitting condition is rather straightforward in the case of power converters. Assume that the output voltage is the control variable. Then, the state variables of the full-order SM controller, which are to be controlled, may be expressed in the following form:

$$
\left[\begin{array}{l}
x_{1} \\
x_{2} \\
x_{3}
\end{array}\right]=\left[\begin{array}{c}
V_{\mathrm{ref}}-\beta v_{\mathrm{o}} \\
\frac{d\left(V_{\mathrm{ref}}-\beta v_{\mathrm{o}}\right)}{d t} \\
\int\left(V_{\mathrm{ref}}-\beta v_{\mathrm{o}}\right) d t
\end{array}\right]
$$

where $V_{\text {ref }}$ and $\beta v_{\mathrm{o}}$ denote the reference and sensed instantaneous output voltages, respectively; and $x_{1}, x_{2}$, and $x_{3}$ are the voltage error, the voltage-error dynamics (or the rate of change of voltage error), and the integral of voltage error, respectively. For the design of the hitting condition, it is sufficient to consider only the immediate state variable $x_{1}$, which is predominant in the composition of $S$ during the reaching phase. Apparently, if the sensed output voltage is much lower than the reference voltage, i.e., $S$ is positive, the intuitive switching action required for the compensation is to turn on the power switch so that the energy is transferred from the input source to the inductor. Conversely, if the sensed output voltage is much higher than the reference voltage, i.e., $S$ is negative, the intuitive switching action is to turn off the power switch so that the energy transfer between the source and the inductor is discontinued. This forms the basis for the formulation of the hitting condition. The resulting control function under the configuration is

$$
u= \begin{cases}1=\text { "ON," } & \text { when } S>0 \\ 0=\text { "OFF," } & \text { when } S<0 .\end{cases}
$$

Clearly, the method of ensuring the hitting condition of the SM controller is similar to the way in which the switching states of the hysteresis controller are designed. Thus, the same approach may be adopted for ensuring the hitting condition of an SM controller which employs the current-mode type of control.

\section{B. Step 2: To Meet Existence Condition}

With the switching states $u^{+} / u^{-}$determined, the next stage is to ensure that the selected sliding coefficients $\alpha_{1}, \alpha_{2}$, and $\alpha_{3}$ comply with the condition for SM existence. This is possible by inspecting the local reachability condition of the state trajectory, i.e.,

$$
\lim _{S \rightarrow 0} S \cdot \dot{S}<0 .
$$

In the case of a buck converter, the substitution of the converter's description into the aforementioned condition gives

$0<L C \frac{\alpha_{3}}{\alpha_{2}}\left(V_{\text {ref }}-\beta v_{\mathrm{o}}\right)-\beta L\left(\frac{\alpha_{1}}{\alpha_{2}}-\frac{1}{r_{\mathrm{L}} C}\right) i_{\mathrm{C}}+\beta v_{\mathrm{o}}<\beta v_{\mathrm{i}}$

where $C, L$, and $r_{\mathrm{L}}$ denote the capacitance, inductance, and instantaneous load resistance of the converters, respectively; $V_{\text {ref }}, v_{\mathrm{i}}$, and $v_{\mathrm{o}}$ denote the reference, instantaneous input, and instantaneous output voltages, respectively; $\beta$ denotes the feedback network ratio; and $i_{\mathrm{C}}$ denotes the instantaneous capacitor current.

Here, $C, L, \beta$, and $V_{\text {ref }}$ are the known parameters of the converter system, and their exact values can be substituted directly into the inequality for inspection. However, for $v_{\mathrm{i}}$ and $r_{\mathrm{L}}$ which typically represent a range of input and output operating conditions that the converter may engage, it is necessary to consider the boundary points of these operating conditions. The compliance of either the maximum or minimum point of these operating conditions is generally sufficient for ensuring the abidance of the existence condition for the entire range of condition. As for $v_{\mathrm{o}}$ and $i_{\mathrm{C}}$, which are the instantaneous state variables, the consideration of the time-varying nature of these components undesirably complicates the evaluation. In the case of designing an SM controller with a static sliding surface, a practical approach is to ensure that the existence condition is met for the steady-state operation [26], [48]. With such considerations, the state variables $i_{\mathrm{C}}$ and $v_{\mathrm{o}}$ can be substituted with their expected steady-state parameters, i.e., $i_{\mathrm{C}(\mathrm{SS})}$ and $v_{\mathrm{o}(\mathrm{SS})}$, which can be derived from the design specification. This assures the compliance of the existence condition at least in the small region around the origin. Taking into consideration all the discussed presumptions, the resulting existence condition is

$$
\begin{array}{r}
0<L C \frac{\alpha_{3}}{\alpha_{2}}\left(V_{\mathrm{ref}}-\beta v_{\mathrm{o}(\mathrm{SS})}\right)-\beta L\left(\frac{\alpha_{1}}{\alpha_{2}}-\frac{1}{r_{\mathrm{L}(\min )} \mathrm{C}}\right) \\
\times i_{\mathrm{C}(\mathrm{SS})}+\beta v_{\mathrm{o}(\mathrm{SS})}<\beta v_{\mathrm{i}(\mathrm{min})}
\end{array}
$$

The selected sliding coefficients must comply with the stated inequality. Similar existence conditions can be derived for other types of converters using the same approach.

\section{Step 3: To Meet Stability Condition}

In addition to the existence condition, the selected sliding coefficients must concurrently abide by the stability condition. This is to ensure that, in the event of SM operation, the created sliding surface will always direct the state trajectory toward a point where a stable equilibrium exists. Interestingly, this can be inherently accomplished through the design of the sliding coefficients to meet the desired dynamical property [71]. This is 


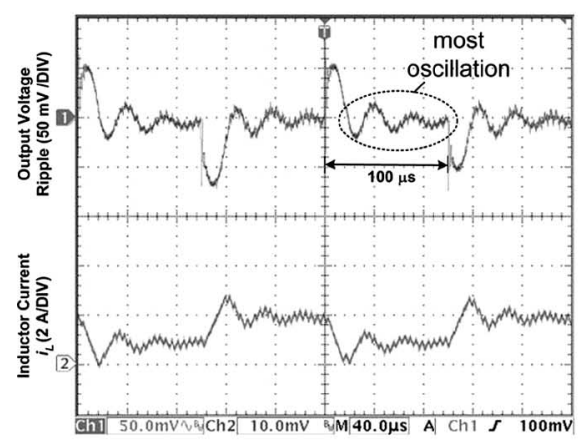

(a)

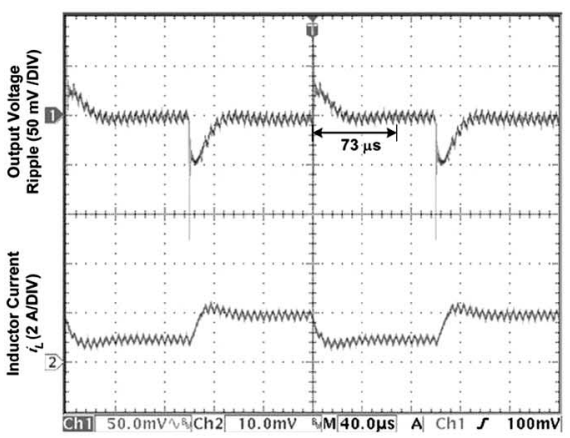

(d)

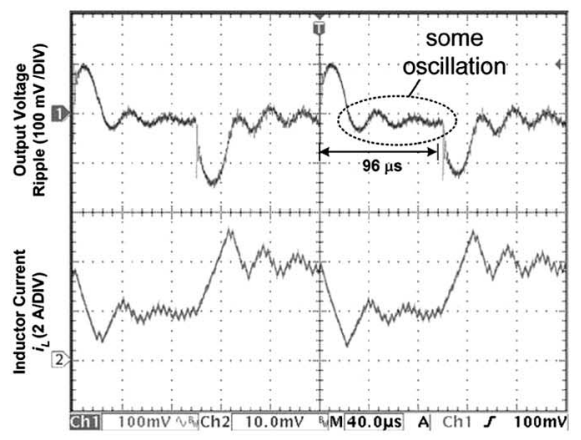

(b)

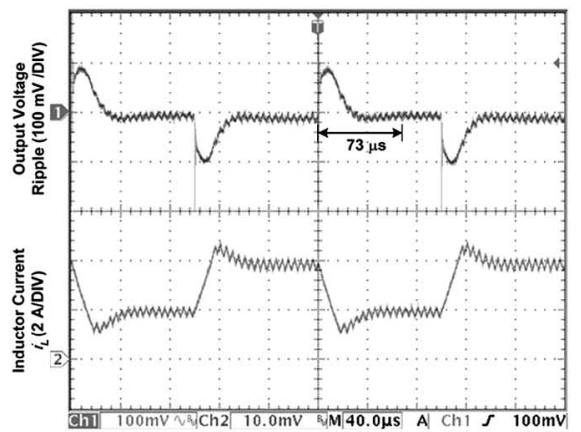

(e)

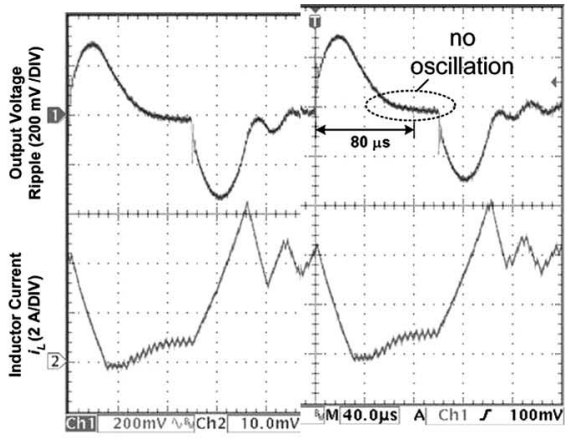

(c)

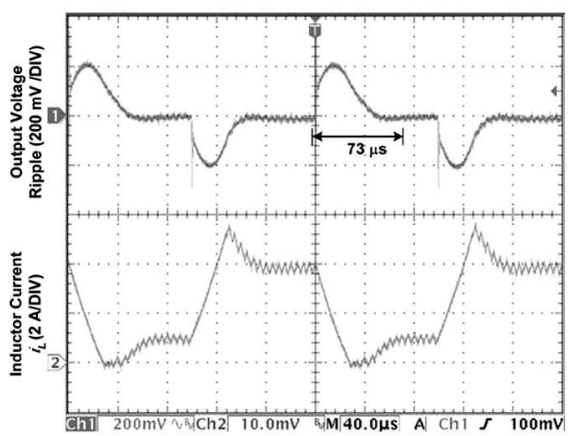

(f)

Fig. 4. Experimental waveforms of output-voltage ripple $\widetilde{v_{\mathrm{O}}}$ and inductor current $i_{\mathrm{L}}$ of the buck converter, with (a)-(c) the classical PWM voltage-mode controller and (d)-(f) the 20-kHz-bandwidth PWM-based SM controller, operating at 5-kHz step-load-resistance change. (a) $R_{\mathrm{L}}$ between 6 and $12 \Omega$ (PWM controller). (b) $R_{\mathrm{L}}$ between 3 and $6 \Omega$ (PWM controller). (c) $R_{\mathrm{L}}$ between 3 and $12 \Omega$ (PWM controller). (d) $R_{\mathrm{L}}$ between 6 and $12 \Omega$ (SM controller). (e) $R_{\mathrm{L}}$ between 3 and $6 \Omega$ (SM controller). (f) $R_{\mathrm{L}}$ between 3 and $12 \Omega$ (SM controller).

possible by using the invariance property. Since it is known that, in SM operation, the state trajectory $S$ will track the path of the sliding surface to a point of stability, an equation describing the dynamical property of the system can be obtained by equating the state trajectory to this sliding surface, i.e., by setting $S=0$. The proper selection of the sliding coefficients will tailor the system to respond as desired by the designer. It follows that the stability condition is inherently met.

In our example, the equation relating the sliding coefficients to the dynamic response of the converter during SM operation is

$$
\alpha_{1} x_{1}+\alpha_{2} \frac{d x_{1}}{d t}+\alpha_{3} \int x_{1} d t=0
$$

This equation can be rearranged into a standard second-order system form in which the design of the sliding coefficients $\alpha_{1}$, $\alpha_{2}$, and $\alpha_{3}$ can result in a system adopting one of these three possible types of responses: underdamped, critically damped, and overdamped, with a desired convergency rate [74]. Hence, designers can easily select the sliding coefficients based on their converters' response time and voltage overshoot specifications. It should be noted that the selected sliding coefficients should comply with the existence condition described in the previous section. Additionally, if $\left(\alpha_{1} / \alpha_{2}\right) \gg\left(1 / r_{\mathrm{L}} \mathrm{C}\right)$, an almost constant dynamical characteristic can be achieved throughout all operating conditions for the SM-operation phase. Likewise, similar steps can be adopted for designing controllers of higher order.

\section{CASE-STUdy EXAMPles AND Discussions}

In this section, experimental results of converters with the conventional PWM controllers and the PWM-based SM voltage controllers are provided as case-study examples to illustrate the difference between a large-signal-controlled system and a small-signal-controlled system.

\section{A. PWM-Based SM Controller Versus Conventional Voltage PWM Controller in Buck Converter}

The dynamic behavior of the PWM-based SMVC buck converter is compared with that of the classical type of PWM voltage-mode-controlled buck converter. In the experiment, the former employs a $20-\mathrm{kHz}$-bandwidth critically damped PWMbased SM controller, whereas the latter employs a TL494 PID PWM voltage-mode controller that is tuned to operate with a critically damped response at a step-load change from $R_{\mathrm{L}}=3 \Omega$ to $R_{\mathrm{L}}=12 \Omega$. Fig. 4(a)-(f) shows the experimental waveforms with both converters operating at $5-\mathrm{kHz}$ step-load change.

With the classical PWM voltage-mode controller, the dynamic behavior of the system is dissimilar at different operating settings. Specifically, the response becomes more oscillatory at lower currents, i.e., the output-voltage ripple waveform in Fig. 4(a) exhibits more oscillation, Fig. 4(b) with less oscillation, and Fig. 4(c) with no oscillation (when entered momentarily into discontinuous conduction mode). This is expected since the PWM controller is designed for a specific operating 


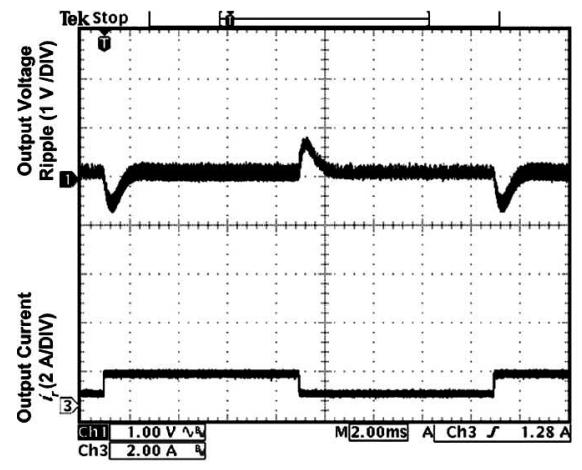

(a)

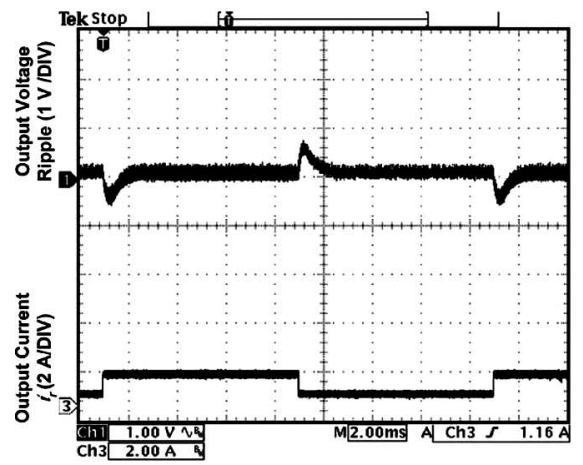

(d)

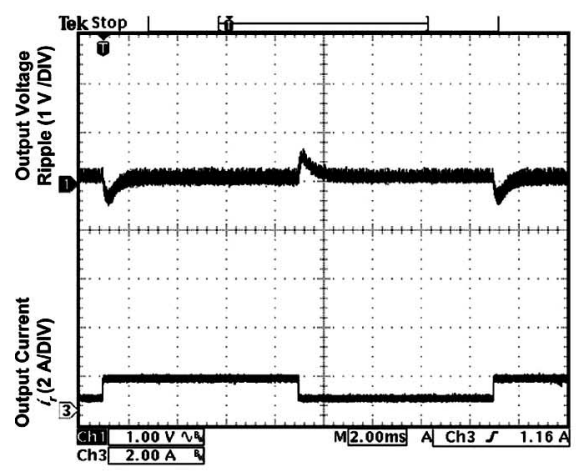

(g)

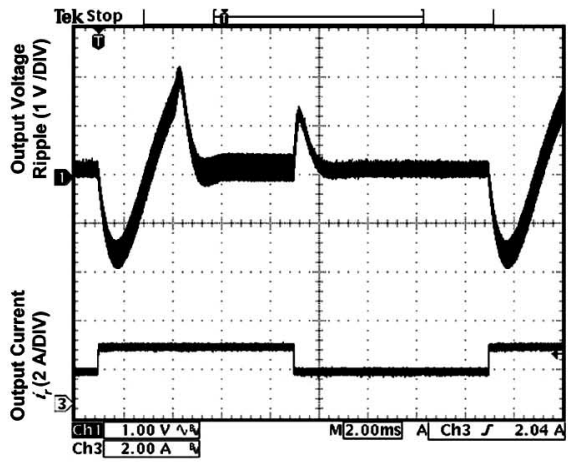

(b)

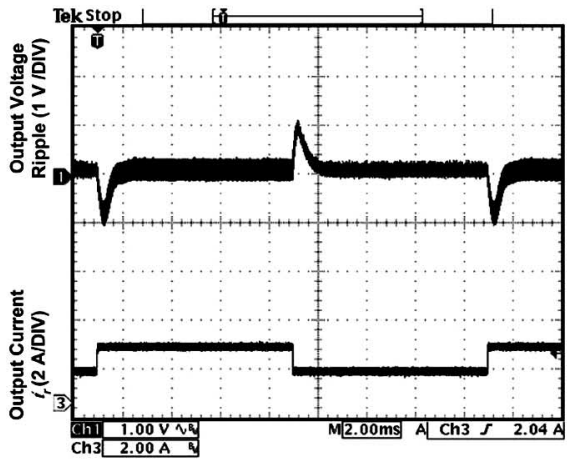

(e)

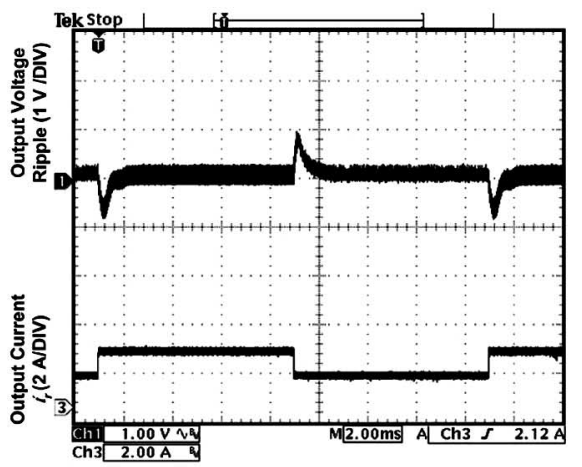

(h)

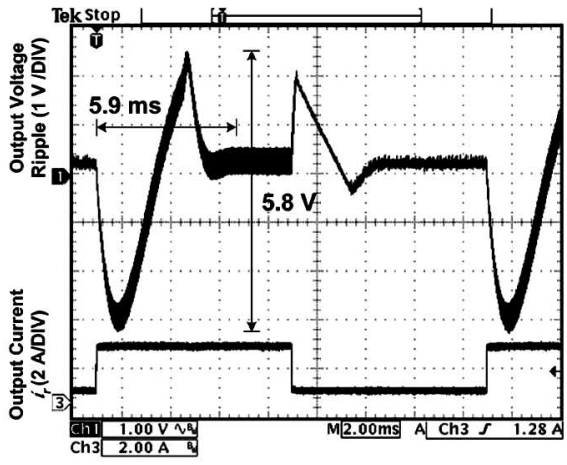

(c)

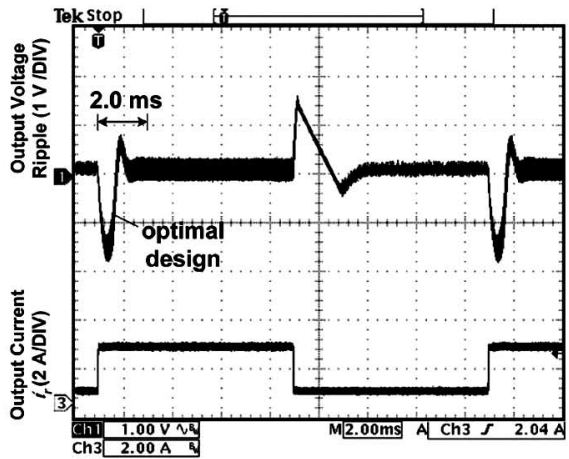

(f)

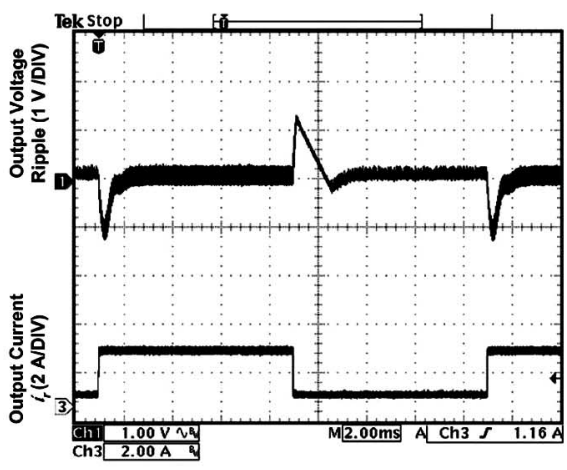

(i)

Fig. 5. Experimental waveforms of output- voltage ripple $\widetilde{v_{\mathrm{O}}}$ and output current $i_{\mathrm{r}}$ of the boost converter with the peak-current-mode controller operating at input voltages of $20 \mathrm{~V}$ (minimum), $24 \mathrm{~V}$ (nominal), and $28 \mathrm{~V}$ (maximum) and alternating between load resistances of $24 \Omega$ (minimum), $48 \Omega$ (half), and $240 \Omega$

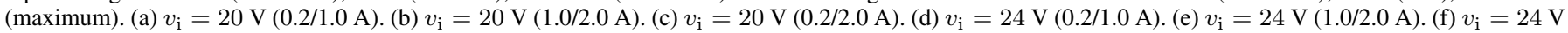
$(0.2 / 2.0 \mathrm{~A}) .(\mathrm{g}) v_{\mathrm{i}}=28 \mathrm{~V}(0.2 / 1.0 \mathrm{~A})$. (h) $v_{\mathrm{i}}=28 \mathrm{~V}(1.0 / 2.0 \mathrm{~A})$. (i) $v_{\mathrm{i}}=28 \mathrm{~V}(0.2 / 2.0 \mathrm{~A})$.

condition, which leads to changes in the response behavior when a different operating condition is engaged.

On the other hand, with the PWM-based SM controller, the dynamic behavior of the output-voltage ripple is basically similar (i.e., critically damped) for all three operating load conditions, even when it enters momentarily into a discontinuous conduction mode and even when it experiences a change in converter's description. This demonstrates an advantage of the SM controller in terms of robustness in the dynamic behavior at different operating conditions and uncertainties. Additionally, the example also illustrates a major difference between a largesignal-controlled system (SM) and a small-signal-controlled system (PWM), i.e., the former complies with the design with a similar response for all operating conditions, whereas the response of the latter will only comply with the design at a specific operating condition.

\section{B. PWM-Based SM Controller Versus Peak-Current-Mode Controller in Boost Converter}

The dynamic behavior of the PWM-based controller is compared with that of a UC3843 peak-current-mode PWM controller that is optimally tuned to operate at the step-load change from $r_{\mathrm{L}}=240 \Omega$ to $r_{\mathrm{L}}=24 \Omega$ for the input condition $v_{\mathrm{i}}=24 \mathrm{~V}$. Fig. 5(a)-(i) shows the experimental waveforms of the peak-current-mode-controlled boost converter operating at a load resistance that alternates between $r_{\mathrm{L}}=24 \Omega$ and $r_{\mathrm{L}}=240 \Omega$ for various input voltages. 


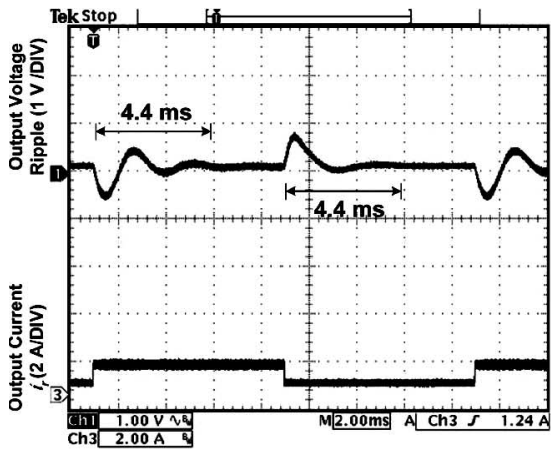

(a)

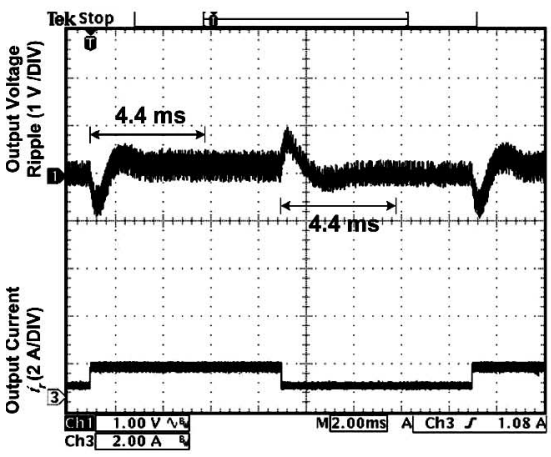

(d)

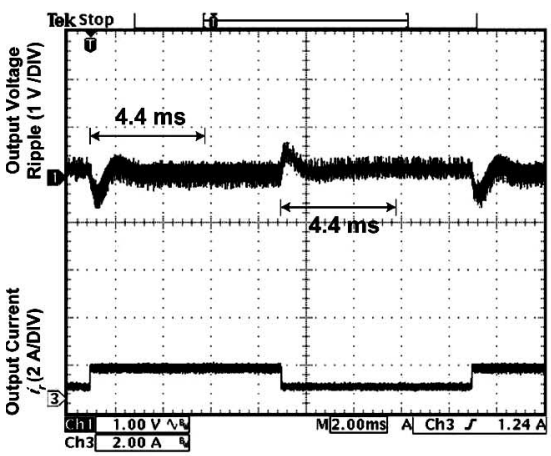

(g)

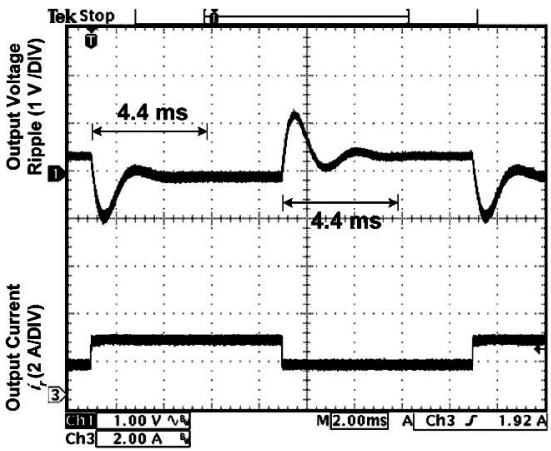

(b)

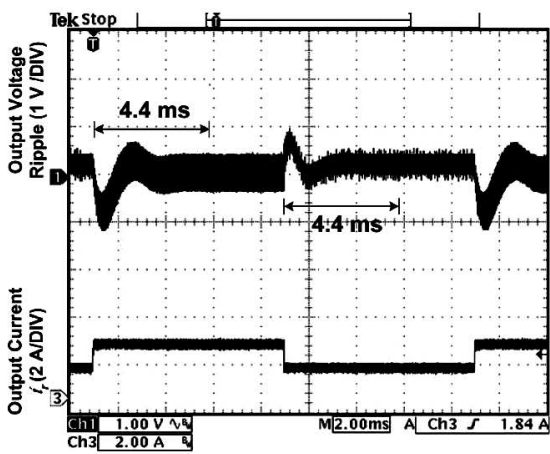

(e)

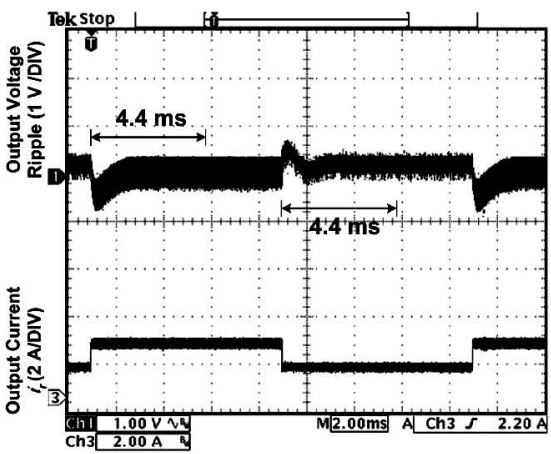

(h)

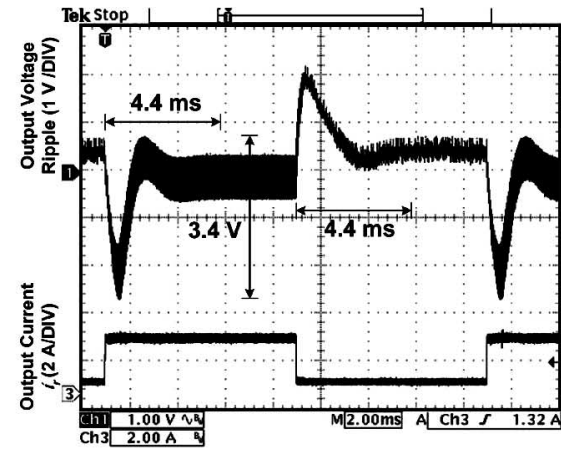

(c)

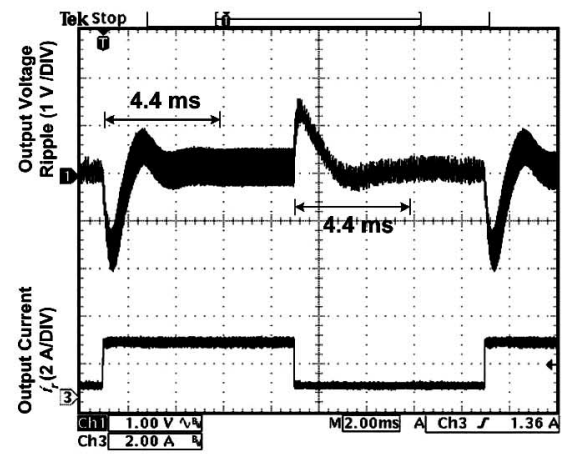

(f)

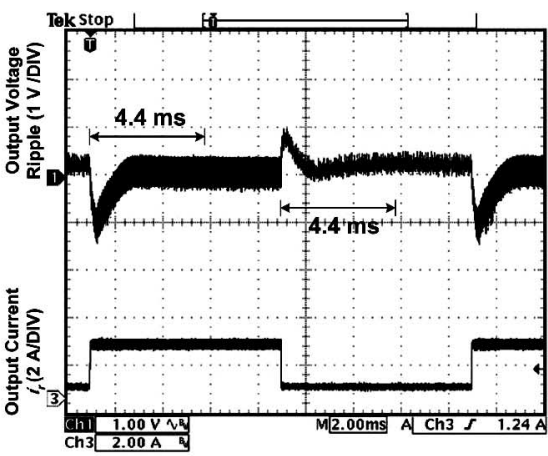

(i)

Fig. 6. Experimental waveforms of output-voltage ripple $\widetilde{v_{\mathrm{O}}}$ and output current $i_{\mathrm{r}}$ of the boost converter with a 1.5-krad/s bandwidth PWM-based SM controller operating at input voltages of $20 \mathrm{~V}$ (minimum), $24 \mathrm{~V}$ (nominal), and $28 \mathrm{~V}$ (maximum) and alternating between load resistances of $24 \Omega$ (minimum), $48 \Omega$ (half), and $240 \Omega$ (maximum). (a) $v_{\mathrm{i}}=20 \mathrm{~V}(0.2 / 1.0 \mathrm{~A})$. (b) $v_{\mathrm{i}}=20 \mathrm{~V}(1.0 / 2.0 \mathrm{~A})$. (c) $v_{\mathrm{i}}=20 \mathrm{~V}(0.2 / 2.0 \mathrm{~A}) .(\mathrm{d}) v_{\mathrm{i}}=24 \mathrm{~V}(0.2 / 1.0 \mathrm{~A}) .(\mathrm{e}) v_{\mathrm{i}}=24 \mathrm{~V}(1.0 / 2.0 \mathrm{~A})$. (f) $v_{\mathrm{i}}=24 \mathrm{~V}(0.2 / 2.0 \mathrm{~A})$. (g) $v_{\mathrm{i}}=28 \mathrm{~V}(0.2 / 1.0 \mathrm{~A})$. (h) $v_{\mathrm{i}}=28 \mathrm{~V}(1.0 / 2.0 \mathrm{~A})$. (i) $v_{\mathrm{i}}=28 \mathrm{~V}(0.2 / 2.0 \mathrm{~A})$.

It can be seen that, with the peak-current-mode PWM controller, the dynamic behavior of the system differs for different operating conditions. Specifically, the response becomes less oscillatory at higher input voltages. Moreover, the dynamic behavior and transient settling time are also different between the various cases of operating conditions. Specifically, at a lower step-current change, i.e., from 0.2 to $1.0 \mathrm{~A}$, the response of the system becomes critically damped, instead of its optimally designed response which is slightly underdamped, as shown in Fig. 5(f). Furthermore, in the worst case operating condition: $v_{\mathrm{i}}=20 \mathrm{~V}$ and step output-current change of $0.2-2.0 \mathrm{~A}$, the system has a settling time of $5.8 \mathrm{~ms}$ and a relatively highvoltage ripple swing of $5.6 \mathrm{~V}$ [see Fig. 5(c)], which are much in deviation from the optimally designed value of $2 \mathrm{~ms}$ and a voltage ripple swing of $2.6 \mathrm{~V}$ [see Fig. 5(f)]. This is expected since the peak-current-mode controller is designed under a linearized small-signal model that is only optimal for a specific operating condition. Thus, when a different operating condition is engaged, the response varies.

On the other hand, with the PWM-based SM controller, the dynamic behavior of the output-voltage ripple is basically similar (i.e., slightly underdamped) for all operating input and load conditions. This is shown in Fig. 6(a)-(i), which shows the experimental waveforms of the PWM-based SM-controlled boost converter operating at the same set of operating conditions as the peak-current-mode-controlled boost converter.

Furthermore, the transient settling time, which is around $4.4 \mathrm{~ms}$, is also independent of the direction and magnitude of the step-load change and the operating input voltages. This coincides with the design which, being a $1.25-\mathrm{krad} / \mathrm{s}$ bandwidth 
controller, is expected to have a settling time of $5 \tau=5 / 1.25=$ $4.0 \mathrm{~ms}$. Moreover, in the worst case operating condition: $v_{\mathrm{i}}=$ $20 \mathrm{~V}$ and step output-current change of 0.2-2.0 A, the settling time is still around $4.4 \mathrm{~ms}$, and the voltage ripple swing is $3.4 \mathrm{~V}$ [see Fig. 6(c)]. This is close to the optimally designed system, which has a voltage ripple swing of $3.0 \mathrm{~V}$ [see Fig. 6(f)]. This illuminates again the strength of the SM controller in terms of robustness in the dynamic behavior at different operating conditions and uncertainties. It also reinforces our belief that the main advantage of the large-signal controller (SM) over the small-signal controller (PWM) is that it gives more consistent dynamic performances for operating conditions requiring wide ranges.

\section{CONCLUSION}

The various aspects concerning the application of slidingmode controllers in dc-dc converters are presented. A comprehensive literature review on the area is provided. The issues related to the analog implementation of the slidingmode controller are discussed. The advantage of using slidingmode controller is highlighted. It is shown that the sliding-mode controllers generate more consistent transient responses for a wide operating range as compared with the conventional linear controllers.

\section{REFERENCES}

[1] V. Utkin, J. Guldner, and J. X. Shi, Sliding Mode Control in Electromechanical Systems. London, U.K.: Taylor \& Francis, 1999.

[2] V. Utkin, Sliding Modes in Control Optimization. Berlin, Germany: Springer-Verlag, 1992.

[3] C. Edwards and S. K. Spurgeron, Sliding Mode Control: Theory and Applications. London, U.K.: Taylor \& Francis, 1998.

[4] W. Perruquetti and J. P. Barbot, Sliding Mode Control in Engineering. New York: Marcel Dekker, 2002.

[5] J. J. E. Slotine and W. Li, "Sliding control," in Applied Nonlinear Control. Englewood Cliffs, NJ: Prentice-Hall, 1991, ch. 7.

[6] M. Comanescu and L. Xu, "Sliding-mode MRAS speed estimators for sensorless vector control of induction machine," IEEE Trans. Ind. Electron., vol. 53, no. 1, pp. 146-153, Feb. 2006.

[7] S. Janardhanan and B. Bandyopadhyay, "Output feedback sliding-mode control for uncertain systems using fast output sampling technique," IEEE Trans. Ind. Electron., vol. 53, no. 5, pp. 1677-1682, Oct. 2006.

[8] F. Betin, A. Sivert, A. Yazidi, and G. A. Capolino, "Determination of scaling factors for fuzzy logic control using the sliding-mode approach: Application to control of a DC machine drive," IEEE Trans. Ind. Electron., vol. 54, no. 1, pp. 296-309, Feb. 2007.

[9] A. V. Topalov, G. L. Cascella, V. Giordano, F. Cupertino, and O. Kaynak, "Sliding mode neuro-adaptive control of electric drives," IEEE Trans. Ind. Electron., vol. 54, no. 1, pp. 671-679, Feb. 2007.

[10] A. M. Lienhardt, G. Gateau, T. A. Meynard, and B. Bandyopadhyay, "Digital sliding-mode observer implementation using FPGA," IEEE Trans. Ind. Electron., vol. 54, no. 4, pp. 1865-1875, Aug. 2007.

[11] R. Venkataramanan, "Sliding mode control of power converters," Ph.D. dissertation, California Inst. Technol., Dept. Elect. Eng., Pasadena, CA, May 1986.

[12] R. D. Middlebrook and S. Ćuk, "A general unified approach to modeling switching-converter power stages," in Proc. IEEE PESC Rec., 1976, pp. $18-34$.

[13] D. M. Mitchell, DC-DC Switching Regulator Analysis. New York: McGraw-Hill, 1998.

[14] A. J. Forsyth and S. V. Mollow, "Modelling and control of DC-DC converters," Power Eng. J., vol. 12, no. 5, pp. 229-236, Oct. 1998.

[15] J. G. Kassakian, M. F. Schlecht, and G. C. Verghese, Principles of Power Electronics. Reading, MA: Addison-Wesley, Jun. 1992.

[16] F. Bilalović, O. Mušić, and A. Šabanović, "Buck converter regulator operating in the sliding mode," in Proc. 7th Int. Conf. PCI, Apr. 1983, pp. 331-340.
[17] R. Venkataramanan, A. Šabanović, and S. Ćuk, "Sliding mode control of DC-to-DC converters," in Proc. IEEE Conf. IECON, 1985, pp. 251-258.

[18] S. P. Huang, H. Q. Xu, and Y. F. Liu, "Sliding-mode controlled Ćuk switching regulator with fast response and first-order dynamic characteristic," in Proc. IEEE PESC Rec., Jun. 1989, pp. 124-129.

[19] E. Fossas, L. Martínez, and J. Ordinas, "Sliding mode control reduces audiosusceptibility and load perturbation in the Ćuk converter," IEEE Trans. Circuits Syst. I, Fundam. Theory Appl., vol. 39, no. 10, pp. 847849, Oct. 1992.

[20] L. Malesani, L. Rossetto, G. Spiazzi, and P. Tenti, "Performance optimization of Cuk converters by sliding-mode control," IEEE Trans. Power Electron., vol. 10, no. 3, pp. 302-309, May 1995.

[21] M. Oppenheimer, M. Husain, M. Elbuluk, and J. A. De Abreu Garcia, "Sliding mode control of the Ćuk converter," in Proc. IEEE PESC Rec., Jun. 1996, vol. 2, pp. 1519-1526.

[22] J. Mahdavi and A. Emadi, "Sliding-mode control of PWM Ćuk converter," in Proc. 6th Int. Conf. Power Electron. Variable Speed Drives, Sep. 1996, vol. 2, pp. 372-377.

[23] J. Calvente, L. Martinez, and R. Giral, "Design of locally stable sliding modes in bidirectional switching converters," in Proc. 40th Midwest Symp. Circuits Syst., Aug. 1997, vol. 1, pp. 615-618.

[24] L. Martinez-Salamero, J. Calvente, R. Giral, A. Poveda, and E. Fossas, "Analysis of a bidirectional coupled-inductor Ćuk converter operating in sliding mode," IEEE Trans. Circuits Syst. I, Fundam. Theory Appl., vol. 45, no. 4, pp. 355-363, Apr. 1998.

[25] P. Mattavelli, L. Rossetto, G. Spiazzi, and P. Tenti, "General-purpose sliding-mode controller for DC/DC converter applications," in Proc. IEEE PESC Rec., Jun. 1993, pp. 609-615.

[26] P. Mattavelli, L. Rossetto, and G. Spiazzi, "Small-signal analysis of DC-DC converters with sliding mode control," IEEE Trans. Power Electron., vol. 12, no. 1, pp. 96-102, Jan. 1997.

[27] F. Dominguez, E. Fossas, and L. Martinez, "Stability analysis of a buck converter with input filter via sliding-mode approach," in Proc. IEEE Conf. IECON, Sep. 1994, pp. 1438-1442.

[28] M. Castilla, L. C. de Vicuna, M. Lopez, O. Lopez, and J. Matas, "On the design of sliding mode control schemes for quantum resonant converters," IEEE Trans. Power Electron., vol. 15, no. 6, pp. 960-973, Nov. 2000.

[29] P. F. Donoso-Garcia, P. C. Cortizo, B. R. de Menezes, and M. A. Severo Mendes, "Sliding mode control for current distribution in DC-to-DC converters connected in parallel," in Proc. IEEE PESC Rec., Jun. 1996, pp. $1513-1518$.

[30] Y. B. Shtessel, O. A. Raznopolov, and L. A. Ozerov, "Sliding mode control of multiple modular DC-to-DC power converters," in Proc. IEEE Int. Conf. Control Appl., Dec. 1996, pp. 685-690.

[31] Y. B. Shtessel, O. A. Raznopolov, and L. A. Ozerov, "Control of multiple modular DC-to-DC power converters in conventional and dynamic sliding surfaces," IEEE Trans. Circuits Syst. I, Fundam. Theory Appl., vol. 45, no. 10, pp. 1091-1100, Oct. 1998.

[32] M. López, L. G. De-Vicuòa, M. Castilla, and J. Majo, "Interleaving of parallel DC-DC converters using sliding mode control," in Proc. IEEE Conf. IECON, Sep. 1998, pp. 1055-1059.

[33] R. Giral, L. Martinez-Salamero, R. Leyva, and J. Maixe, "Sliding-mode control of interleaved boost converters," IEEE Trans. Circuits Syst. I, Fundam. Theory Appl., vol. 47, no. 9, pp. 1330-1339, Sep. 2000.

[34] S. K. Mazumder, A. H. Nayfeh, A. Borojevic, P. Gaya, and O. López, "Robust control of parallel DC-DC buck converters by combining integralvariable-structure and multiple-sliding-surface control schemes," IEEE Trans. Power Electron., vol. 17, no. 3, pp. 428-437, May 2002.

[35] M. López, L. G. De-Vicun̆a, M. Castilla, P. Gaya, and O. López, "Current distribution control design for paralleled DC/DC converters using slidingmode control," IEEE Trans. Ind. Electron., vol. 51, no. 2, pp. 419-428, Apr. 2004.

[36] H. Sira-Ramirez and M. Rios-Bolivar, "Sliding mode control of DCto-DC power converters via extended linearization," IEEE Trans. Circuits Syst. I, Fundam. Theory Appl., vol. 41, no. 10, pp. 652-661, Oct. 1994.

[37] H. Sira-Ramirez, R. Ortega, R. Perez-Moreno, and M. Garcia-Esteban, "A sliding mode controller-observer for DC-to-DC power converters: A passivity approach," in Proc. 34th IEEE Conf. Decision Control, Dec. 1995, pp. 3379-3384.

[38] H. Sira-Ramirez, G. Escobar, and R. Ortega, "On passivity-based sliding mode control of switched DC-to-DC power converters," in Proc. 35th IEEE Conf. Decision Control, Dec. 1996, pp. 2525-2526.

[39] E. Fossas and D. Biel, "A sliding mode approach to robust generation on DC-to-DC nonlinear converters," in Proc. IEEE Int. Workshop Variable Struct. Syst., Dec. 1996, pp. 67-71. 
[40] J. M. Carrasco, J. M. Quero, F. P. Ridao, M. A. Perales, and L. G. Franquelo, "Sliding mode control of a DC/DC PWM converter with PFC implemented by neural networks," IEEE Trans. Circuits Syst. I, Fundam. Theory Appl., vol. 44, no. 8, pp. 743-749, Aug. 1997.

[41] S. A. Bock, J. R. Pinheiro, H. Grundling, H. L. Hey, and H. Pinheiro, "Existence and stability of sliding modes in bi-directional DC-DC converters," in Proc. IEEE PESC Rec., Jun. 2001, vol. 3, pp. 1277-1282.

[42] E. Fossas and A. Pas, "Second order sliding mode control of a buck converter," in Proc. 41 st IEEE Conf. Decision Control, Dec. 2002, vol. 1, pp. 346-347.

[43] Y. B. Shtessel, A. S. I. Zinober, and I. A. Shkolnikov, "Boost and buck-boost power converters control via sliding modes using method of stable system centre," in Proc. 41st IEEE Conf. Decision Control, Dec. 2002, vol. 1, pp. 340-345.

[44] Y. B. Shtessel, A. S. I. Zinober, and I. A. Shkolnikov, "Boost and buck-boost power converters control via sliding modes using dynamic sliding manifold," in Proc. 41 st IEEE Conf. Decision Control, Dec. 2002, vol. 3, pp. 2456-2461.

[45] N. Vazquez, C. Hernandez, J. Alvarez, and J. Arau, "Sliding mode control for DC/DC converters: A new sliding surface," in Proc. IEEE Int. Symp. Ind. Electron., Jun. 2003, vol. 1, pp. 422-426.

[46] P. Gupta and A. Patra, "Hybrid sliding mode control of DC-DC power converter circuits," in Proc. IEEE Region Ten Conf. Convergent Technol. Asia-Pac. Region, Oct. 2003, vol. 1, pp. 259-263.

[47] H. Sira-Ramirez, "Sliding mode- $\Delta$ modulation control of a "buck converter"," in Proc. 42nd IEEE Conf. Decision Control, Dec. 2003, vol. 3, pp. 2999-3004.

[48] H. Sira-Ramirez, "On the generalized PI sliding mode control of DCto-DC power converters: A tutorial," Int. J. Control, vol. 76, no. 9/10, pp. 1018-1033, 2003.

[49] V. S. C. Raviraj and P. C. Sen, "Comparative study of proportionalintegral, sliding mode, and fuzzy logic controllers for power converters," IEEE Trans. Ind. Appl., vol. 33, no. 2, pp. 518-524, Mar./Apr. 1997.

[50] D. Cortes and J. Alvarez, "Robust sliding mode control for the boost converter," in Proc. IEEE Int. CIEP Power Electron. Congr., Oct. 2002, pp. 208-212.

[51] C. Morel, J. C. Guignard, and M. Guillet, "Sliding mode control of DCto-DC power converters," in Proc. 9th Int. Conf. Electron., Circuits Syst., Sep. 2002, vol. 3, pp. 971-974.

[52] C. Morel, "Slide mode control via current mode control in DC-DC converters," in Proc. IEEE Int. Conf. Syst., Man, Cybern., Oct. 2002, vol. 5, pp. 6-11.

[53] C. Morel, "Application of slide mode control to a current-mode-controlled boost converter," in Proc. IEEE Conf. IECON, Nov. 2002, vol. 3, pp. 1824-1829.

[54] G. Escobar, R. Ortega, H. Sira-Ramirez, J. P. Vilain, and I. Zein, "An experimental comparison of several nonlinear controllers for power converters," IEEE Control Syst. Mag., vol. 19, no. 1, pp. 66-82, Feb. 1999.

[55] H. Chiacchiarini, P. Mandolesi, and A. Oliva, "Nonlinear analog controller for a buck converter: Theory and experimental results," in Proc. IEEE Int. Symp. Ind. Electron., Jul. 1999, pp. 601-606.

[56] E. Alarcon, A. Romero, A. Poveda, S. Porta, and L. Martinez-Salamero, "Sliding-mode control analog integrated circuit for switching DC-DC power converters," in Proc. IEEE Int. Symp. Circuits Syst., May 2001, pp. 500-503.

[57] M. Ahmed, M. Kuisma, K. Tolsa, and P. Silventoinen, "Implementing sliding mode control for buck converter," in Proc. IEEE PESC Rec., Jun. 2003, vol. 2, pp. 634-637.

[58] M. Ahmed, M. Kuisma, P. Silventoinen, and O. Pyrhonen, "Effect of implementing sliding mode control on the dynamic behavior and robustness of switch mode power supply (buck converter)," in Proc. 5th Int. Conf. Power Electron. Drive Syst., Nov. 2003, vol. 2, pp. 1364-1368.

[59] M. Ahmed, M. Kuisma, O. Pyrhonen, and P. Silventoinen, "Sliding mode control for buck-boost converter using control desk dSPACE," in Proc. 5th Int. Conf. Power Electron. Drive Syst., Nov. 2003, vol. 2, pp. 1491-1494.

[60] B. J. Cardoso, A. F. Moreira, B. R. Menezes, and P. C. Cortizo, "Analysis of switching frequency reduction methods applied to sliding mode controlled DC-DC converters," in Proc. IEEE APEC, Feb. 1992, pp. 403-410.

[61] V. M. Nguyen and C. Q. Lee, "Tracking control of buck converter using sliding-mode with adaptive hysteresis," in Proc. IEEE PESC Rec., Jun. 1995, vol. 2, pp. 1086-1093.

[62] V. M. Nguyen and C. Q. Lee, "Indirect implementations of sliding-mode control law in buck-type converters," in Proc. IEEE APEC, Mar. 1996, vol. 1 , pp. 111-115.
[63] J. Mahdavi, A. Emadi, and H. A. Toliyat, "Application of state space averaging method to sliding mode control of PWM DC/DC converters," in Proc. Conf. Rec. IEEE IAS Annu. Meeting, Oct. 1997, vol. 2, pp. 820-827.

[64] J. Mahdavi, M. R. Nasiri, and A. Agah, "Application of neural networks and state-space averaging to a DC/DC PWM converter in sliding mode operation," in Proc. IEEE Conf. IECON, 2000, vol. 1, pp. 172-177.

[65] A. G. Perry, F. Guang, Y. F. Liu, and P. C. Sen, "A new sliding mode like control method for buck converter," in Proc. IEEE PESC Rec., Jun. 2004, vol. 5, pp. 3688-3693.

[66] L. Iannelli and F. Vasca, "Dithering for sliding mode control of DC/DC converters," in Proc. IEEE PESC Rec., Jun. 2004, vol. 2, pp. 1616-1620.

[67] S. K. Mazumder and S. L. Kamisetty, "Experimental validation of a novel multiphase nonlinear VRM controller," in Proc. IEEE PESC Rec., Jun. 2004, pp. 2114-2120.

[68] J. Matas, L. G. De-Vicuňa, O. López, and M. López, "Discrete sliding mode control of a boost converter for output voltage tracking," in Proc. 8th Int. Conf. Power Electron. Variable Speed Drives, Sep. 2000, pp. 351-354.

[69] R. Orosco and N. Vazquez, "Discrete sliding mode control for DC/DC converters," in Proc. IEEE Int. CIEP Power Electron. Congr., Oct. 2000, pp. 231-236.

[70] S. C. Tan, Y. M. Lai, M. K. H. Cheung, and C. K. Tse, "On the practical design of a sliding mode voltage controlled buck converter," IEEE Trans. Power Electron., vol. 20, no. 2, pp. 425-437, Mar. 2005.

[71] J. Ackermann and V. Utkin, "Sliding mode control design based on Ackermann's formula," IEEE Trans. Autom. Control, vol. 43, no. 2, pp. 234-237, Feb. 1998.

[72] H. Sira-Ramirez, "A geometric approach to pulse-width modulated control in nonlinear dynamical systems," IEEE Trans. Autom. Control, vol. 34, no. 2, pp. 184-187, Feb. 1989.

[73] L. Martinez, A. Poveda, J. Majo, L. Garcia-de-Vicuna, F. Guinjoan, J. C. Marpinard, and M. Valentin, "Lie algebras modeling of bidirectional switching converters," in Proc. ECCTD, Sep. 1993, vol. 2, pp. 1425-1429.

[74] S. C. Tan, Y. M. Lai, C. K. Tse, and M. K. H. Cheung, "A fixed-frequency pulse-width-modulation based quasi-sliding mode controller for buck converters," IEEE Trans. Power Electron., vol. 20, no. 6, pp. 1379-1392, Nov. 2005.

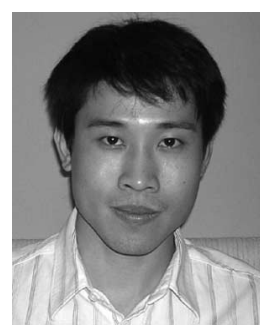

Siew-Chong Tan (S'00-M'06) received the B.Eng. (with honors) and M.Eng. degrees in electrical and computer engineering from the National University of Singapore, Singapore, in 2000 and 2002, respectively, and the Ph.D. degree from Hong Kong Polytechnic University, Kowloon, Hong Kong, in 2005.

$\mathrm{He}$ worked briefly as a Research Associate and then as a Postdoctoral Fellow with the Department of Electronic and Information Engineering, Hong Kong Polytechnic University, where he is currently a Lecturer. His research interests include motor drives and power electronics.

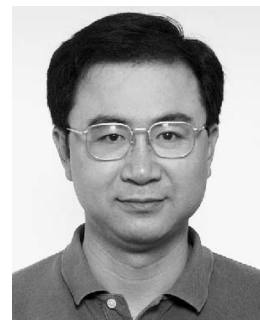

Y. M. Lai (M'92) received the B.Eng. degree in electrical engineering from the University of Western Australia, Perth, Australia, in 1983, the M.Eng.Sc. degree in electrical engineering from the University of Sydney, Sydney, Australia, in 1986, and the Ph.D. degree from Brunel University, Uxbridge, U.K., in 1997.

$\mathrm{He}$ is an Assistant Professor with Hong Kong Polytechnic University, Kowloon, Hong Kong. His research interests include computer-aided design of power electronics and nonlinear dynamics. 


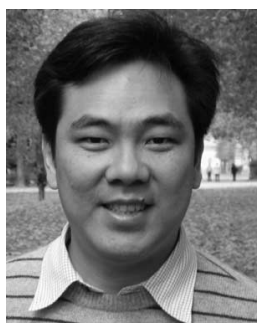

Chi K. Tse (M'90-SM'97-F'06) received the B.Eng. (Hons.) degree (with first class honors) in electrical engineering and the $\mathrm{Ph} . \mathrm{D}$. degree from the University of Melbourne, Melbourne, Australia, in 1987 and 1991, respectively.

$\mathrm{He}$ is currently a Chair Professor with and the Head of the Department of Electronic and Information Engineering, Hong Kong Polytechnic University, Kowloon, Hong Kong. He is a Guest Professor with Wuhan University, Wuhan, China, and Southwest University, Chongqing, China. His research interests include power electronics, complex networks, and nonlinear systems. $\mathrm{He}$ is the Author of Linear Circuit Analysis (Addison-Wesley 1998) and Complex Behavior of Switching Power Converters (CRC Press, 2003), the Coauthor of Chaos-Based Digital Communication Systems (Springer-Verlag, 2003) and Chaotic Signal Reconstruction with Applications to Chaos-Based Communications (TUP, 2005), and the Coholder of a U.S. patent and two pending patents. In 1987, he was awarded the L.R. East Prize by the Institution of Engineers, Australia, the IEEE Transactions on Power Electronics Prize Paper Award in 2001, and the International Journal of Circuit Theory and Applications Best Paper Award in 2003. In 2007, he is awarded the Distinguished International Research Fellowship by the University of Calgary, Calgary, AB, Canada. While with Hong Kong Polytechnic University, he received twice the President's Award for Achievement in Research, the Faculty's Best Researcher Award, the Research Grant Achievement Award, and a few other teaching awards. From 1999 to 2001, he served as an Associate Editor for the IEEE Transactions on Circuits and Systems Part I-Fundamental THEORY AND APPLICATIONS, and since 1999, he has been an Associate Editor for the IEEE TRANSACTIONS ON POWER ELECTRONICS. In 2005, he served as an IEEE Distinguished Lecturer. Currently, he also serves as the Editor-inChief of the IEEE Circuits and Systems Society Newsletter, the Associate Editor for the International Journal of Systems Science, and the Guest Editor of a few other journals. 